\title{
A gamificação e o desenvolvimento de competências socioemocionais em sala de aula
}

\author{
Gamification and the development of socio-emotional skills in the classroom
}

Gamificación y desarrollo de competencias socioemocionales en el aula

Tulio Augusto Andrade Oliveira ORCID: https://orcid.org/0000-0002-8098-311X Uniesp Centro Universitário, Brasi E-mail: tulioaugusto@hotmail.com

Karol Costa Guedes

ORCID: https://orcid.org/0000-0001-7967-3061 Universidade Federal da Paraíba, Brasil E-mail: karolcostaguedes@hotmail.com

Kylven Costa Guedes

ORCID: https://orcid.org/0000-0002-8348-5319 Igreja Presbiteriana de Tambaú, Brasil

E-mail: kylven@gmail.com

Karen Guedes Oliveira

ORCID: https://orcid.org/0000-0003-2970-5349 Universidade Federal da Paraíba, Brasil

E-mail: karen_costaguedes@hotmail.com

\begin{abstract}
Resumo
As demandas comunicativas do século XXI caracterizam-se pelos novos recursos tecnológicos que dão forma às expressões humanas cada vez mais enviesadas pelo enorme fluxo informacional suscitado pelos processos globalizantes. Nesse contexto, encontra-se o público jovem que, ressignificando cada vez mais as novas formas de comunicação, requer novos modos de aprender. A partir da gamificação, competências socioemocionais podem ser desenvolvidas em sala de aula, posto que, no processo de gamificação, o estudante vê-se em situações em que precisa saber lidar consigo, com o outro e com os desafios propostos. Como problemática desta pesquisa, questionase: que estratégia gamificadora pedagógica pode ser utilizada para o desenvolvimento de uma aprendizagem mais significativa em indivíduos que se constroem socioemocionalmente competentes? Para isso, objetiva-se revisar teoricamente as noções sobre gamificação, competências socioemocionais e sujeito responsivo e responsável, para que seja possível, então, propor uma estratégia de desenvolvimento do ensino-aprendizagem a partir da gamificação, por meio de um olhar atento ao desenvolvimento de competências socioemocionais dos estudantes. Por meio de uma metodologia bibliográfica, exploratória, qualitativa e propositiva, esta pesquisa fundamenta-se em estudos sobre 1) competências socioemocionais (Del Prette \& Del Prette, 2001; Pena, Alves, Primi, 2020); 2) gamificação e ensinoaprendizagem; e 3) a interação dialógico-discursiva do indivíduo responsivo e responsável (Bakhtin, 2010, 2016). Consideram-se profícuas as reflexões sobre os novos desafios do ensino-aprendizagem hoje, através de uma estratégia pedagógica colaborativa que suscita o fortalecimento mental e o desenvolvimento socioemocional em atividade interativa de compreensões ativas.
\end{abstract}

Palavras-chave: Competências socioemocionais; Gamificação; Ensino-aprendizagem; Sujeito responsivo e responsável.

\begin{abstract}
The communicative demands of the 21 st century is characterized by new technological resources that shape human expressions that are increasingly biased by the enormous informational flow generated by globalizing processes. In this context, there is the young people that, increasingly resignifying new forms of communication, requires new ways of learning. From gamification, social-emotional skills can be developed in the classroom, given that, in the gamification process, the student finds himself in situations where he needs to know how to deal with himself, with the other and with the proposed challenges. As a problem of this research, the question is: what pedagogical gamification strategy can be used for the development of a more significant learning in individuals who build themselves socio-emotionally competent? For this, the objective is to theoretically review the notions about gamification, socio-emotional skills and a responsive and responsible subject, so that it is possible, then, to propose a teaching-learning development strategy based on gamification, through a careful look at development of students' socio-emotional skills. Through a bibliographical, exploratory, qualitative and propositional methodology, this research is based on studies on 1) socio-emotional skills (Del Prette \& Del Prette, 2001; Pena, Alves, Primi, 2020); 2) gamification and teaching-learning; and 3) the dialogic-discursive interaction of the responsive and responsible
\end{abstract}


individual (Bakhtin, 2010, 2016). Reflections on the new challenges of teaching and learning today are considered fruitful, through a collaborative pedagogical strategy that raises mental strengthening and socio-emotional development in an interactive activity of active understandings.

Keywords: Socio-emotional skills; Gamification; Teaching-learning; Responsive and responsible subject.

\section{Resumen}

Las demandas comunicativas del siglo XXI se caracterizan por nuevos recursos tecnológicos que configuran expresiones humanas cada vez más sesgadas por el enorme flujo informativo que generan los procesos globalizadores. En este contexto, está el público joven que, cada vez más resignificando nuevas formas de comunicación, requiere nuevas formas de aprendizaje. A partir de la gamificación se pueden desarrollar competencias socioemocionales en el aula, ya que, en el proceso de gamificación, el alumno se encuentra en situaciones en las que necesita saber enfrentarse a sí mismo, al otro y a los retos propuestos. Como problema de esta investigación, la pregunta es: ¿qué estrategia de gamificación pedagógica se puede utilizar para el desarrollo de un aprendizaje más significativo en individuos que se construyen socioemocionalmente competentes? Para ello, el objetivo es revisar teóricamente las nociones sobre gamificación, competencias socioemocionales y un sujeto receptivo y responsable, para que sea posible, entonces, proponer una estrategia de desarrollo de enseñanzaaprendizaje basada en la gamificación, a través de una atenta mirada a desarrollo de las competencias socioemocionales de los estudiantes. Mediante una metodología bibliográfica, exploratoria, cualitativa y proposicional, esta investigación se basa en estudios sobre 1) competencias socioemocionales (Del Prette \& Del Prette, 2001; Pena, Alves, Primi, 2020); 2) gamificación y enseñanza-aprendizaje; y 3) la interacción dialógicodiscursiva del individuo receptivo y responsable (Bakhtin, 2010, 2016). Las reflexiones sobre los nuevos desafíos de la enseñanza y el aprendizaje en la actualidad se consideran fructíferas, a través de una estrategia pedagógica colaborativa que plantea el fortalecimiento mental y el desarrollo socioemocional en una actividad interactiva de entendimientos activos.

Palabras clave: Competencias socioemocionales; Gamificación; Enseñanza-aprendizaje; Sujeto receptivo y responsable.

\section{Introdução}

A gamificação no contexto da relação ensino-aprendizagem se traduz como uma rica possibilidade de colaborar para o processo educativo, seja no contexto infanto-juvenil, seja no contexto de educação de adultos. Estudos sobre tal relação inferem que o importante no conhecimento não é o conceito aprendido. Ao contrário, são as estratégias utilizadas para assimilar esse conceito e a utilização do elemento aprendido que dão sentido ao aprendizado, facilitando-o (Meira \& Blikstein, 2020).

Por meio da gamificação, o comportamento de cooperação é verificado com frequência nas relações interpessoais dos jogadores. Entendida como uma maneira especial de trabalhar em conjunto, McGonigal (2017) destaca três habilidades que podem ser desenvolvidas em jogos colaborativos: 1) Cooperação (agir intencionalmente em prol de uma meta comum), 2 Coordenação (sincronizar esforços e compartilhar recursos) e 3) Cocriação (produzir coletivamente um novo resultado). Isto é, por meio do esforço mútuo, é possível criar, aprender e transformar uma situação, solucionar um desafio e ainda desenvolver mais competências socioemocionais.

O desempenho social é verificado examinando as relações entre o contexto - desempenho - consequências. Ou seja, para a avaliação das competências sociais, os critérios, elencados por Del Prette e Del Prette (2001), são: 1) a consecução de objetivos, isto é, se o indivíduo consegue expressar o que está sentindo ou obter o que pretendia da relação; 2) a manutenção ou melhoria da relação interpessoal; 3) a manutenção ou melhoria da autoestima; 4) o respeito e defesa dos direitos humanos básicos (reconhecer o próprio direito e respeitar os direitos dos demais); e 5) busca de equilíbrio nas relações interpessoais, resguardando a igualdade na relação.

Pesquisas têm demonstrado que pessoas com maiores níveis de habilidades socioemocionais apresentam atitudes mais positivas em relação a si mesmo, incluindo maior autoestima, autoefiácia, maior persistência frente a objetivos, melhores relacionamentos interpessoais, maior comprometimento e desempenho escolar (Damásio, 2017). 
Nesse sentido, as competências socioemocionais são consideradas nesse estudo a partir das diretrizes do Collaborative for Academic, Social, and Emotional Learning (CASEL), o qual consiste em uma organização sem fins lucrativos, formada por uma equipe pioneira de pesquisadores, que, há mais de 26 anos, se dedicam à avaliação do impacto das habilidades socioemocionais ao longo do ciclo vital e desenvolvem programas que investem na aprendizagem socioemocional de cinco habilidades a serem desenvolvidas: autoconhecimento, autorregulação, consciência social, habilidades de relacionamento e tomada de decisões responsável.

Desse modo, tais habilidades podem estar evidentemente relacionadas com o processo ensino-aprendizagem, pois identificar as próprias emoções, identificar e utilizar estratégias para lidar com o estresse, demonstrar compaixão e empatia, além de ter uma comunicação efetiva com outras pessoas e antecipar e avaliar as consequências de suas ações são competências que fortalecem o ser humano enquanto sujeito com suas características pessoais e ajudam em sua relação com o outro e com o ambiente. A competência social capacita o indivíduo para "organizar pensamentos, sentimentos e ações em função de seus objetivos e valores articulando-os às demandas imediatas e mediatas do ambiente" (Del Prette \& Del Prette, 2001, p. 31).

Sendo assim, o ensino deve favorecer uma participação mais ativa do estudante no processo educativo. Deve-se estimular as atividades lúdicas como meio pedagógico que, junto com outras atividades, auxiliam na criatividade para vencer os desafios da vida. Então, as características do jogo fazem com que ele mesmo seja um veículo de aprendizagem e comunicação ideal para o desenvolvimento da personalidade e da inteligência emocional de quem aprende (Murcia, 2005).

Bakhtin (2010b) defende que todo indivíduo é responsivo, por meio da interação dialógica discursiva que o constitui, e responsável, pelo fato de, mesmo sob diversas influências e trocas socio-históricas e culturais, imprimir, ativamente, o significado que deseja nos enunciados que produz, diz e silencia. Deve-se, portanto, levar em consideração que são estudantes ativos, socialmente constituídos e dialógicos com os quais o docente lida constantemente em sala de aula.

Desse modo, o presente estudo tem como objetivo revisar teoricamente as noções sobre gamificação, competências socioemocionais e sujeito responsivo e responsável, para que seja possível, então, propor uma estratégia de desenvolvimento do ensino-aprendizagem a partir da gamificação, por meio de um olhar atento ao desenvolvimento de competências socioemocionais dos estudantes.

A pesquisa bibliográfica, exploratória, qualitativa e propositiva foi estruturada na apresentação dos resultados e discussão seguindo a organização: Inicialmente, uma discussão sobre as competências socioemocionais (Pena, Alves, Primi, 2020; Del Prette \& Del Prette, 2001), em seguida, a apresentação da gamificação e sua relação com o ensino-aprendizagem e, por último, uma reflexão sobre a interação dialógico-discursiva do indivíduo responsivo e responsável (Bakhtin, 2010, 2016) que aprende de forma crítica, criativa e participativa.

\section{Metodologia}

Esta pesquisa é de natureza básica, já que objetiva gerar conhecimentos úteis para o avanço da ciência. Quanto aos objetivos, trata-se de uma pesquisa exploratória, com a finalidade de proporcionar mais informações sobre o assunto investigado.

Esta pesquisa é feita bibliograficamente, uma vez que é elaborada a partir da contribuição de teóricos e outras pesquisas que tematizam sobre o assunto em interesse. Do ponto de vista da forma de abordagem do problema, esta pesquisa é qualitativa, já que a descrição e a análise fazem parte, de forma interpretativa, da discussão proposta, a partir da atribuição de significados, não traduzidos em números. 
Além das caracterizações feitas acima, faz-se necessário pontuar que esta pesquisa é, também, propositiva, já que é feita uma proposição prática da vida real educacional, a fim de atenuar um problema social que envolve o uso da gamificação para o desenvolvimento de competências socioemocionais dos estudantes.

Foram utilizados os fundamentos teóricos das competências socioemocionais, da gamificação e do processo de ensino-aprendizagem, e da interação dialógico-discursiva do indivíduo responsivo e responsável.

\section{Resultados e Discussão}

\section{Competências socioemocionais}

Ao longo da história do Ocidente, especialmente no período pós-iluminista, a escola tradicional valorizou o desenvolvimento cognitivo como sendo o principal objetivo do processo ensino-aprendizagem, privilegiando o pensamento lógico e a transmissão dos conteúdos (Morin, 2000). No entanto, tem-se percebido a necessidade do trabalho com as competências socioemocionais em todas as etapas do desenvolvimento humano, sendo, inclusive, consideradas aliadas ao desenvolvimento cognitivo e prático dos estudantes, noção reafirmada na Base Nacional Comum Curricular (BNCC), atual documento que preconiza um currículo básico para o pleno desenvolvimento do indivíduo em sua integralidade.

Homologado pelo Ministério da Educação e Cultura (MEC) em 2018, a BNCC é fruto da mobilização e contribuição participativa de profissionais de todos os estados brasileiros e de 35 universidades brasileiras, que se dispuseram a pensar uma educação que contemple toda a população brasileira de forma igualitária, respeitadas a diversidade e as particularidades de cada região. Trata-se de um conjunto de diretrizes ancoradas na Lei de Diretrizes e Bases (LDB), sancionada em 1996, e no Plano Nacional de Educação (PNE), aprovado em 2014, que são instrumentos forjados a impulsionarem o desenvolvimento educacional, para atendimento das demandas sociopolíticas e pedagógicas do país, para nortear a construção curricular das mais de 190 mil escolas de Educação Básica espalhadas de Norte a Sul, públicas ou particulares. (Brasil, 2018)

Percebe-se um heterodiscurso presente na BNCC que se constrói tendo em vista a necessidade de esclarecimento previsto pelo PNE, acerca de conhecimentos, competências e habilidades de cada nível de ensino e de cada área de conhecimento mobilizados no currículo escolar. As ideias dialogadas acerca desse documento preveem a necessidade de interação entre sujeitos que se constituem responsáveis e responsivos frente ao ensino-aprendizagem na educação básica, que constroem identidades, produzem conhecimento e agem de forma crítica no mundo.

A ideia presente na Base acerca de sujeitos responsáveis e responsivos, construtores de identidades, produtores de conhecimento e agentes críticos no mundo, através da linguagem, nos permite buscar compreender as relações dialógicas de um ser como um vir a ser (Bakhtin, 2010a), isto é, como um acontecimento, compreendido como um não emaranhado de generalizações, previamente constituído, mas como um processo ininterrupto de constituição, através do mundo das ações, das vivências.

A fim de ponderar sobre a relevância do desenvolvimento das competências socioemocionais na Educação Básica, especificamente no nível do Ensino Médio, faz-se necessária a compreensão/conceituação de competência. Na BNCC, competência é definida como "a mobilização de conhecimentos (conceitos e procedimentos), habilidades (práticas, cognitivas e socioemocionais), atitudes e valores para resolver demandas complexas da vida cotidiana, do pleno exercício da cidadania e do mundo do trabalho" (Brasil, 2018, p. 8).

A BNCC aponta para a caracterização do estudante do Ensino Médio a partir de uma visão chamada, no documento, de não homogeneizante, que compreende a juventude como condição sócio-histórica-cultural de uma categoria de sujeitos que necessita ser considerada em suas múltiplas dimensões. Ampliando essa concepção de juventude para categorizar o sujeito compreendido como estudante do Ensino Médio, a Base ratifica a constituição desse sujeito por meio de uma educação que 
deve "afirmar valores e estimular ações que contribuam para a transformação da sociedade, tornando-a mais humana e socialmente justa” (Brasil, 2013, p. 16).

Destaca-se, como competências socioemocionais que devem ser desenvolvidas na vida escolar do estudante:

8. Conhecer-se, apreciar-se e cuidar de sua saúde física e emocional, compreendendo-se na diversidade humana e reconhecendo suas emoções e as dos outros, com autocrítica e capacidade para lidar com elas.

9. Exercitar a empatia, o diálogo, a resolução de conflitos e a cooperação, fazendo-se respeitar e promovendo o respeito ao outro e aos direitos humanos, com acolhimento e valorização da diversidade de indivíduos e de grupos sociais, seus saberes, identidades, culturas e potencialidades, sem preconceitos de qualquer natureza.

10. Agir pessoal e coletivamente com autonomia, responsabilidade, flexibilidade, resiliência e determinação, tomando decisões com base em princípios éticos, democráticos, inclusivos, sustentáveis e solidários (Brasil, 2018, p. 10).

A competência social qualifica, avaliativamente, a proficiência de um desempenho. Isto é, trata-se de verificar a capacidade do indivíduo na "organização de pensamentos, sentimentos e ações, em função de seus objetivos e valores, articulando-os às demandas imediatas e mediatas do ambiente” (Del Prette \& Del Prette 2001, p. 31).

As competências socioemocionais revelam-se como um conjunto de características pessoais no âmbito das emoções e relações sociais em sua interação com pensamento e inteligência em três núcleos centrais: regulação e controle voluntário do comportamento e motivação, regulação emocional e habilidades interpessoais. Isto é, saber lidar consigo mesmo, com o outro e com os desafios. Por isso, utilizar metodologias que ajudem a desenvolver essas competências pode apresentar efeitos positivos para o desenvolvimento dos estudantes. (Pena, Alves, \& Primi, 2020).

Para isso, realocar os papeis e as responsabilidades dos protagonistas educacionais (professor e estudante) torna-se tarefa indispensável, possível, segundo Abed (2014), por meio de uma mudança nas concepções de ser humano, de ensino, de aprendizagem e de conhecimento. Para a autora, as teorias baseadas nas abordagens interacionistas dialogam com essa noção do universo do ensino e da aprendizagem, uma vez que concebem o ser humano como parte significativa de um processo contínuo de construção, desconstrução e reconstrução nas e pelas interações sociais.

Teóricos como Piaget, Vygotsky, Wallon, Winnicott e Feuerstein oferecem bases para refletir sobre diferentes aspectos inerentes à integração entre as habilidades cognitivas e socioemocionais.

A fim de compreender o universo em que estão inseridas as competências socioemocionais, faz-se necessário deter-se ao que postulam Schultz e Schultz (2011), que conceituam a personalidade como um agrupamento permanente e peculiar de características que podem sofrer modificações, dependendo das situações que o indivíduo esteja vivenciando. Nesse sentido, é importante ressaltar o papel das influências ambientais e da aprendizagem na variação de uma situação para diferentes indivíduos.

Nesse contexto, destaca-se o modelo dos Cinco Grandes Fatores (CGF), que vem sendo sugerido como uma versão atual da Teoria de Traço, e apresenta dimensões básicas da personalidade de forma consistente, também conhecidas como “Big Five", quais sejam: abertura à mudança/experiência (pessoas que tendem a ser mais criativas e inovadoras e apresentam pensamentos mais flexíveis e interesses culturais), conscienciosidade (pessoas que apresentam organização e persistência; são mais prudentes e conscientes de seus deveres), extroversão (os indivíduos mais sociáveis, comunicativos e afetivos), amabilidade (pessoas que, geralmente, são amorosas e generosas, com comportamentos pró-sociais e bondosos) e neuroticismo (caracterizado pela instabilidade emocional e reflete a maior sensibilidade aos estímulos temíveis) (Benet-Martinez, John, 1998; Nunes, Hutz, 2007; Schultz \& Schultz, 2011; Deyoung \& Gray, 2009).

Pensar nos traços de personalidade e sua relação com as competências socioemocionais permite compreender um ambiente escolar como possibilidade para aprimorar o aprendizado, de forma ampla, ao passo em que o bem-estar dos discentes pode contribuir para aperfeiçoar as suas características individuais. 


\section{A gamificação e o ensino-aprendizagem}

Falar sobre gamificação implica refletir sobre o significado dos games na vida do ser humano. Considerado ainda mais antigo que as próprias formações culturais, visto que cultura pressupõe a existência da sociedade humana, o game mostrase presente de modo instintivo no próprio mundo animal, uma vez que os animais se utilizam de atitudes e gestos de força controlada que parecem um certo ritual do brincar.

Mais do que uma manifestação biológica, a gamificação é uma função significante que faz parte da vida do indivíduo:

Tanto a psicologia quanto a filosofia procuram investigar o jogo com o objetivo de entender sua natureza e de alguma forma situá-lo no sistema da vida. Nota-se que há muitas divergências na tentativa de se definir a função biológica do jogo e as três mais frequentes são: descarga de energia vital super abundante; satisfação de um certo instinto de imitação; necessidade de distensão (Alves, 2015, p. 18).

De modo geral, o game é, segundo Huizinga (2004), uma atividade voluntária, que acontece dentro de limites de tempo e de espaço, conforme regras livremente consentidas, porém obrigatórias, dotado de um fim em si mesmo, acompanhado de um sentimento de tensão e de alegria e de uma consciência de ser diferente da vida cotidiana.

Outra definição de game mais inserida em um contexto de aprendizagem, em Kapp (2014), serve de base para a compreensão sobre a gamificação. Para o autor, o game é um sistema em que jogadores se engajam num desafio abstrato, definido por regras, interatividade e feedback, gerando um resultado quantificável frequentemente, proporcionando uma reação emocional.

Observa-se que a perspectiva do feedback aproxima o game de uma experiência de aprendizagem, essencial para o acompanhamento da evolução do que se aprende. Como menciona Alves (2015), existem características dos games, pontuadas pela designer de games Jane McGonigal, que todos gostariam de encontrar em modelos organizacionais, são eles: 1) os games têm meta, isto é, resultado específico que se espera de um jogador, o que dá ao participante um senso de propósito; 2) os games têm regras que estabelecem como chegar ao resultado, o que estimula o jogador a explorar o pensamento estratégico e a criatividade, competências, hoje, essenciais nas empresas de sucesso; 3) os games apresentam um sistema de feedback, informando ao jogador quando a meta está se aproximando, o que motiva o participante a continuar jogando, estimulando à continuação; 4) a participação nos games é voluntária, o que implica a participação e alinhamento de pessoas diferentes jogando juntas, as quais vivenciam uma tensão proposital que promove o desafio prazeroso.

Com vistas a pintar um quadro contextualizado sobre a importância da gamificação para a aprendizagem, observe-se as ênfases explicativas trazidas por Alves (2015):

Se há uma palavra-chave que não poderia ficar de fora em nossa definição esta é engajamento. Afinal, trata-se da meta explícita dos sistemas gamificados. Principalmente quando o assunto é aprendizagem em uma época em que facilitadores, professores e palestrantes disputam a atenção de seus aprendizes com a tecnologia. Quanto ao público ou audiência, estas pessoas são os indivíduos que queremos ver engajados em nosso sistema gamificado e cuja ação queremos motivar. E motivar a ação é o nosso desafio. Para mobilizarmos pessoas para a execução de tarefas, solução de problemas e mudança de comportamento, é necessário que os desafios criados tenham seu grau de dificuldade ajustado de tal forma que não provoquem o efeito contrário (Alves, 2015, pp. 27-28).

Segundo Piccini (2015), o cérebro humano é dividido em dois hemisférios, e cada um possui suas peculiaridades e funções no organismo do indivíduo. O hemisfério esquerdo é caracterizado por ter áreas responsáveis pelo raciocínio lógico, fala, matemática, linhas etc. Pode ser chamado de "cérebro acadêmico", já o hemisfério direito possui áreas responsáveis pelo gosto à música, arte, dança, criatividade, arte etc. Esse é o seu “cérebro artístico". Ambos os hemisférios são ligados pelo corpo caloso, um sistema de transmissão químico que trabalha, a toda velocidade, com milhares de células. Quanto maior a 
sintonia entre os hemisférios, mais forte se torna a conexão no corpo caloso, e essa conexão fortificada ajuda o ser humano a raciocinar com mais rapidez, além de permitir uma melhora significativa em sua memorização. Daí a noção de que, brincando, há aprendizagem, uma vez que os indivíduos são sujeitos ativos, responsivos e responsáveis.

Nessa perspectiva, pode-se pensar a gamificação também como dialógica, isto é, como uma estratégia didática, contribuindo, diretamente, para o desenvolvimento da aprendizagem ativa. Além do mais, propõe que professores e estudantes, juntos, se mantenham aptos/abertos para a mudança, para a aquisição de novos processos de aprendizagem e mudanças, a partir dessa nova perspectiva de aquisição e aprimoramento do conhecimento (Alzani \& Alves, 2020).

\section{Sujeitos responsivos e responsáveis: indivíduos ativos}

Toda comunicação ou interação humana verbal ocorre por meio da troca de enunciados, essencialmente sob a forma de um diálogo (Volóchinov, 2019). E tais enunciados são essencialmente responsivos, dada sua natureza dialógica. Toda palavra enunciada "espera" resposta, seja esta resposta dita ou silenciada. Em nossas percepções mentais, os discursos vão sendo interiormente produzidos, justamente pela necessidade responsiva de enunciar, comunicar, dialogar, a partir de um movimento anterior conhecido, pelos estudos bakhtinianos, como interpretação responsiva.

Para Bakhtin (2015), a interpretação responsiva trata-se de uma interpretação ativa, força essencial para a formação de todo e qualquer discurso, seja ele de resistência ou de apoio, a partir de contraidentificações ou desidentificações. Para que um discurso seja produzido, uma compreensão responsiva ativa é desenvolvida, isto porque são processos que ocorrem em indivíduos constituídos de linguagem, assimilação, opinião, avaliação e, portanto, valoração.

Segundo o filósofo, "viver a partir de si não significa viver para si, mas significa ser, a partir de si, responsavelmente participante, afirmar o seu não-álibi real e compulsório no existir" (Bakhtin, 2010b, p. 108). Isto é, todo indivíduo é responsivo, por meio da interação dialógica discursiva que o constitui, e responsável, pelo fato de, mesmo sob diversas influências e trocas socio-históricas e culturais, imprimir, ativamente, o significado que deseja nos enunciados que produz, diz e silencia.

A própria BNCC, ao apontar o papel do ensino médio na formação dos sujeitos, cita o artigo 35 da lei 9394/96 da $\mathrm{LDB}^{1}$, a fim de ratificar as expectativas do processo de ensino-aprendizagem na formação do sujeito crítico, quando afirma que se espera que a compreensão do mundo, por parte do indivíduo, se estenda a produções de sentido mais abrangentes e complexas, uma vez que é no desenvolvimento educacional em que se deve oferecer ao estudante condições para ampliar, consolidar e complementar sua formação, contribuindo, especialmente, para o desenvolvimento de suas capacidades de abstração, reflexão, interpretação, proposição e ação, essenciais à autonomia pessoal, profissional, intelectual e política.

Levando em consideração as noções sobre as competências socioemocionais e seu desenvolvimento no processo educacional do estudante; a gamificação e o ensino-aprendizagem; e a interação dialógico-discursiva do indivíduo que se constitui enquanto sujeito responsivo e responsável, dá-se prosseguimento à discussão sobre uma proposta de utilização da gamificação em sala de aula, e a reflexão sobre o impacto que as competências socioemocionais podem causar durante tal estratégia metodológica inovadora, colaborativa e ativa.

\footnotetext{
${ }^{1}$ I - a consolidação e o aprofundamento dos conhecimentos adquiridos no ensino fundamental, possibilitando o prosseguimento de estudos; II - a preparação básica para o trabalho e a cidadania do educando, para continuar aprendendo, de modo a ser capaz de se adaptar com flexibilidade a novas condições de ocupação ou aperfeiçoamento posteriores;

III - o aprimoramento do educando como pessoa humana, incluindo a formação ética e o desenvolvimento da autonomia intelectual e do pensamento crítico;

IV - a compreensão dos fundamentos científico-tecnológicos dos processos produtivos, relacionando a teoria com a prática, no ensino de cada disciplina.
} 


\section{Proposta de utilização da gamificação em sala de aula e o impacto das competências socioemocionais no processo de ensino-aprendizagem}

A estratégia que propomos para que - além do desenvolvimento de determinados objetos de conhecimento, de competências e habilidades específicas da unidade curricular e do segmento educacional em que o docente se situa - haja uma maior ativação dos estudantes, a partir do trabalho colaborativo, lúdico e gamificado, e, consequentemente, competências socioemocionais sejam desenvolvidas no processo, é a Rotação por Estações.

A Rotação por Estações é uma proposta de atividade que promove aprendizagem ativa, por meio do trabalho colaborativo e do desenvolvimento de competências socioemocionais como empatia, confiança, autonomia, solução de conflitos e tomada de decisão responsável. Essa estratégia requer certa mudança no layout da sala de aula: espaços para trabalho em times, seja em carteiras dispostas circularmente ou utilização do próprio chão para um trabalho mais despojado e “dirty hands". Cada espaço (que será ocupado por todos os times, cada um ao seu tempo) chamar-se-á "estação". Em cada estação, haverá uma proposta diferente de atividade (com comando simples e claro) sobre o tema de uma aula dialogada já ocorrida. Todos os times deverão passar por todas as estações, como uma espécie de circuito em sala de aula.

O docente solicita que a turma se divida em times (ou ele mesmo pode fazer uma espécie de sorteio para a formação dos times, para que a interação ocorra fora da zona de conforto do estudante) e comunica o tempo máximo que deverá ser utilizado por todos, em cada estação. O docente deverá utilizar cronômetro (de preferência visível para toda a turma, ou comunicado sobre a passagem de cada minuto). Essa informação da passagem do tempo ao longo de cada estação contribui para a formação de uma atmosfera gamificada, competitiva. Certamente, hormônios como endorfina, dopamina, serotonina, ocitocina e adrenalina já começarão a ser produzidos no corpo de cada estudante, pelo estímulo do docente durante o processo de gamificação.

Além do fator tempo, outro elemento que contribui para um satisfatório desenvolvimento da atividade é a presença do fator recompensa, que pode ser oferecida, se executadas todas as estações corretamente dentro do tempo estipulado, em forma de prêmio (doces, souvenirs, pontuação extra em avaliação de participação).

É importante ressaltar que as estações do circuito devem manter independência cronológica entre si, de modo que se torna possível o desenvolvimento simultâneo dos grupos mediante as orientações de cada estação (ou seja, não importa por qual estação o time começará, ele deverá passar por todos, não importando a ordem de execução dos comandos).

O bom ânimo do docente, ao informar sobre a passagem do tempo cronometrado, ao utilizar efeitos musicais durante a rotação e demais elementos da atividade, deve estimular os estudantes para o bom desenvolvimento da atividade. Palavras de encorajamento e dicas de organização do trabalho são sempre bem-vindas. Ao final da atividade desenvolvida, deverá ser oportunizado um momento de autoavaliação (dos estudantes) e feedback, dos estudantes para o docente, para que seja possível proporcionar a transcendência do "aqui e agora", favorecendo o discente a pensar sobre as implicações do que está sendo "dito e feito", trazendo propósito reflexivo para o processo de ensino-aprendizagem. Esse feedback pode ser feito por meio de um simples questionário (escrito ou oral), que poderá ser utilizado pelo docente para verificar a valoração dos indivíduos sobre a atividade desenvolvida.

Ao utilizar a Rotação por Estações, o docente propiciará aos estudantes a oportunidade de trabalharem colaborativamente, a partir de tomadas de decisão coletiva, responsabilidade na execução de cada comando, já que a atividade precisa ser desenvolvida coletivamente para ser possível ser finalizada no tempo solicitado, além do desenvolvimento de outras competências socioemocionais como a empatia do estudante, ao compreender que determinado colega possui mais afinidade com determinados comandos em detrimento de outros, a confiança, ao serem delegadas as funções de cada componente do time no cumprimento de cada tarefa, todos eles sendo desenvolvidos naturalmente no processo da atividade, a partir de elementos de gamificação, que contribuem para uma memorização mais eficiente dos objetos de conhecimento abordados. 
Segue, abaixo, exemplo da proposta.

Figura 1 - Exemplo de Rotação por Estações.

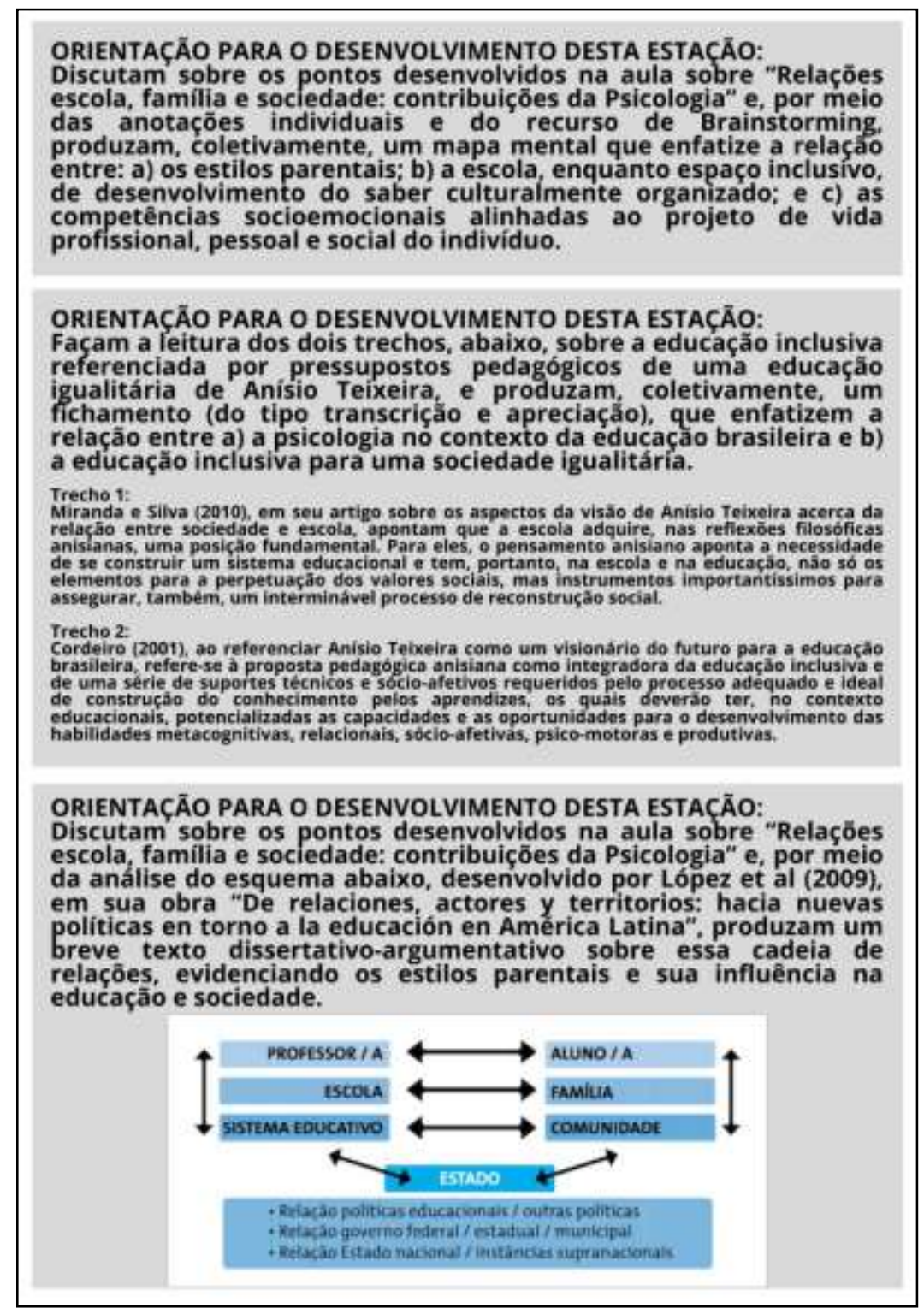

Fonte: Autores.

\section{Considerações Finais}

"Que estratégia gamificadora pedagógica pode ser utilizada para o desenvolvimento de uma aprendizagem mais significativa em indivíduos que se constroem socioemocionalmente competentes?". Com o objetivo de revisar teoricamente as noções sobre gamificação, competências socioemocionais e sujeito responsivo e responsável, para que pudesse ser possível, então, responder ao questionamento supracitado, foi proposta a Rotação por Estações enquanto estratégia de desenvolvimento do ensino-aprendizagem a partir da gamificação, por meio de um olhar atento ao desenvolvimento de competências socioemocionais dos estudantes.

Considera-se que o tema discutido conduz ao desafio de enxergar o processo de ensino-aprendizagem sob uma nova ótica, levando em consideração não a simples transferência de conhecimento, por parte do docente, para alunos assujeitados, 
não iluminados e passivos, mas a concepção de uma aprendizagem ativa, por estudantes ativos, dialógicos, responsivos, responsáveis, em constante interação com os outros, consigo e com o mundo em que estão inseridos.

Sendo assim, a Rotação por Estações é vista como uma possibilidade para que as interações sociais, dialógicas e ativas produzam maior sentido na consolidação dos objetos de conhecimento por parte dos estudantes, a partir do desenvolvimento de competências socioemocionais trabalhadas colaborativamente.

\section{Contribuições para trabalhos futuros}

O que foi trabalhado neste artigo não se encerra aqui, uma vez que, como proposta futura, maiores aprofundamentos podem ser feitos, tanto nas formas específicas de aprendizagem a partir da Rotação por Estações, quanto em uma possível verificação quantitativa de índices hormonais dos estudantes durante a execução da estratégia pedagógica proposta, visando à eficácia da aprendizagem a longo prazo. Analisar a relação entre o desenvolvimento das competências socioemocionais e a elevação de tais níveis orgânicos também produziria satisfatório aprofundamento para a continuação de estudos sobre o tema em questão, o que produz grande relevância para o avanço científico da educação.

\section{Referências}

Abed, A. (2014). O desenvolvimento das habilidades socioemocionais como caminho para a aprendizagem e o sucesso escolar de alunos da educação básica. São Paulo: UNESCO/MEC.

Alves, F. (2015). Gamification: como criar experiências de aprendizagem engajadoras - um guia completo: do conceito à prática. 2. ed. São Paulo: DVS Editora.

Ausani, P. C.; Alves, M. A. (2020). Gamificação e ensino: o jogo dialógico como estratégia didática ativa e inovadora. Research, Society and Development, [S l.], v. 9, n. 6, p. e139962736. DOI: 10.33448/rsd-v9i6.2736. Disponível em: https://rsdjournal.org/index.php/rsd/article/view/2736. Acesso em: 16 jun. 2021.

Bakhtin, M. (2010a). Estética da criação verbal. Tradução de Paulo Bezerra. 5. Ed. São Paulo: Martins Fontes.

Bakhtin, M. (2010b). Para uma filosofia do ato responsável. Tradução aos cuidados de Valdemir Miotello e Carlos Alberto Faraco. São Carlos: Pedro e João Editores.

Bakhtin, M. (2015). Teoria do romance I: a estilística. São Paulo: Editora 34.

Bakhtin, M. (2016). Os gêneros do discurso. Organização, tradução, posfácio e notas de Paulo Bezerra. Notas a edição russa de Serguei Botcharov. São Paulo: Editora 34.

Benet-Martínez, V. \& John, O. P. (1998). Los cinco grandes across cultures and ethnic groups: Multitrait-multimethod analyses of the big five in Spanish and English. Journal of Personality and Social Psychology.

Brasil. (2018). Ministério da Educação. Base Nacional Comum Curricular. Brasília.

Brasil. (2013). Secretaria de Direitos Humanos da Presidência da República. Caderno de Educação em Direitos Humanos. Educação em Direitos Humanos: Diretrizes Nacionais. Brasília: Coordenação Geral de Educação em SDH/PR, Direitos Humanos, Secretaria Nacional de Promoção e Defesa dos Direitos Humanos. <http://portal.mec.gov.br/index.php?option=com_docman\&view=download\&alias=32131-educacao-dh-diretrizesnacionaispdf\&Itemid=30192>.

Damásio, B. F. (2017). Mensurando habilidades socioemocionais de crianças e adolescentes: desenvolvimento e validação de uma bateria (nota técnica). Temas psicol., Ribeirão Preto.

Del Prette, Z. A. P. \& Del Prette, A. (2001). Inventário de Habilidades Sociais (IHS-Del-Prette): Manual de Aplicação, Apuração e Interpretação. São Paulo: Casa do Psicólogo ( $3^{\text {a }}$. edição, com apuração informatizada, em 2006 - Acompanhado de Manual, Caderno de Aplicação e Fichas de Resposta).

Deyoung, C. G. \& Gray, J. R. (2009). Personality neuroscience: Explaining individual differences in affect, behavior, and cognition. In P. J. Corr \& G. Matthews (Eds.), The Cambridge Handbook of Personality Psychology, New York: Cambridge University Press.

Huizinga, J. (2004). Homo ludens: o jogo como elemento da cultura. São Paulo: Perspectiva.

Kapp, K. M. (2014). The Gamification of Learning and Instruction Fieldbook: Ideas into Practice. San Francisco: Wiley.

Mcgonigal, j. (2017). A realidade em jogo. Editora best seller.

Meira, 1. \& Blikstein, p. (2020). Ludicidade, jogos digitais e gamificação na aprendizagem. Porto alegre-rs: artmed.

Morin, Edgar. (2000). A inteligência da complexidade. São Paulo: Peirópolis. 
Research, Society and Development, v. 10, n. 7, e45110716799, 2021

(CC BY 4.0) | ISSN 2525-3409 | DOI: http://dx.doi.org/10.33448/rsd-v10i7.16799

Murcia, J. A. M. (2005). Aprendizagem através do jogo. Porto Alegre-RS: Artmed.

Nunes, C. H. S. S. \& Hutz, C. S. (2007). Construção e validação da Escala Fatorial de Socialização no Modelo dos Cinco Grandes Fatores. Psicologia: Reflexão e Crítica.

Pena, A. C., Alves, G., \& Primi, R. (2020). Habilidades socioemocionais na educação atual. B. Téc. Senac, Rio de Janeiro.

Piccini, L. (2015). Como seu cérebro aprende. Mato Grosso do Sul.

Schultz, S. E. \& Schultz, D. P. (2011). Teorias da personalidade. São Paulo: Cengage Learning.

Volóchinov, V. (2019). A palavra na vida e a palavra na poesia: ensaios, artigos, resenhas e poemas. São Paulo: Editora 34. 